\title{
Real and Fitted Spherical Indentations
}

\author{
Gerd Kaupp \\ University of Oldenburg, Oldenburg, Germany \\ Email: gerd.kaupp@uni-oldenburg.de
}

How to cite this paper: Kaupp, G. (2020) Real and Fitted Spherical Indentations. Advances in Materials Physics and Chemistry, 10, 207-229.

https://doi.org/10.4236/ampc.2020.1010016

Received: August 22, 2020

Accepted: October 7, 2020

Published: October 10, 2020

Copyright $\odot 2020$ by author(s) and Scientific Research Publishing Inc. This work is licensed under the Creative Commons Attribution International License (CC BY 4.0).

http://creativecommons.org/licenses/by/4.0/

\begin{abstract}
Spherical indentations that rely on original date are analyzed with the physically correct mathematical formula and its integration that take into account the radius over depth changes upon penetration. Linear plots, phase-transition onsets, energies, and pressures are algebraically obtained for germanium, zinc-oxide and gallium-nitride. There are low pressure phase-transitions that correspond to, or are not resolved by hydrostatic anvil onset pressures. This enables the attribution of polymorph structures, by comparing with known structures from pulsed laser deposition or molecular beam epitaxy and twinning. The spherical indentation is the easiest way for the synthesis and further characterization of polymorphs, now available in pure form under diamond calotte and in contact with their corresponding less dense polymorph. The unprecedented results and new possibilities require loading curves from experimental data. These are now easily distinguished from data that are "fitted" to make them concur with widely used unphysical Johnson's formula for spheres (" $P=(4 / 3) h^{3 / 2} R^{1 / 2} E^{*}$ ”) not taking care of the $R / h$ variation. Its challenge is indispensable, because its use involves "fitting equations" for making the data concur. These faked reports (no "experimental" data) provide dangerous false moduli and theories. The fitted spherical indentation reports with radii ranging from 4 to $250 \mu \mathrm{m}$ are identified for PDMS, GaAs, $\mathrm{Al}, \mathrm{Si}$, $\mathrm{SiC}, \mathrm{MgO}$, and Steel. The detailed analysis reveals characteristic features.
\end{abstract}

\section{Keywords}

Spherical Indentations, Correct Formula, Phase-Transition Onset Pressure, False Johnson Formula, Detection of Data Fittings

\section{Introduction}

The spherical indentations were not described by H. Hertz, who only deduced that the pressure of a contacting sphere is related to "impact" area ${ }^{3 / 2}$, but without 
any depth (h) upon indentation [1] [2]. When the penetration depth was also considered, all involved researchers tried with "elastic theory" with respect to the area (but not to the volume). The not practically useable mathematical formalism became extremely complicated, using a multitude of most extended mathematical techniques with always hundreds of complicated equations, apparently only readable by highly trained mathematicians. Also, Sneddon reported in 1965 a still very complicated hardly usable multi-term and multi-exponent equation in [3] that was forgotten, when Johnson in 1985 presented his simple (but false) " $P=(4 / 3) h^{3 / 2} R^{1 / 2} E^{*}$ ” formula for spherical indentations [4]. It promised an easy analysis and direct way to the reduced "Young's modulus" and avoidance of very complicated mathematics. This was highly acclaimed and later taken up into the ISO 14577 standard. This formula was thus used by most authors for spherical indentations by citing [1] [2] [4] without checking content and validity. That is rather strange, because the experimental data of spherical indentations exclude the validity of this formula and every simple circle directly shows its incorrectness: it does not consider the enormous $R / h$ changes during the penetration. For example, the $R / h$ ratios in [5] vary from $>1500$ to 20 (for $h_{\max }=20$ $\mathrm{nm}$ ) or from $>480$ to 50 (for $h_{\max }=3.6 \mu \mathrm{m}$ ). Every researcher should have immediately seen that any $R / h$ term is missing in Johnson's formula and that a cone or a pyramid behaves different from a sphere. The second obvious error is claiming "Young's modulus" that is a unidirectional property, totally different from an indentation modulus. A very complex "equation for fitting" of the depth values is published as equation (9) in (6):

$$
\delta-\delta_{\text {contact }}=a_{0}^{2} / R\left\{\left[1+\left(1-P / P_{\text {adh }}\right)^{1 / 2} / 2\right]\right\}^{4 / 3}-2 a_{0}^{2} / 3 R\left\{\left[1+\left(1-P / P_{\text {adh }}\right)^{1 / 2} / 2\right]\right\}^{1 / 3}
$$

The $\delta$ in [6] is penetration depth; $P$ is "load" (force). The "fit parameters" are $a_{0}$ and $P_{\text {adh }}$. This data-falsification is published in [6] together with a series of crazy modulus values, relying on them. Related other fitting equations might also be in use. Only few authors published true experimental data of spherical indentations. These publications will be analyzed and the wealth of their loading curves is used in Section 3 on the basis of the physically and mathematically correct Equation (1), as deduced in [5] [7]. These honest papers concentrate on Bradby's group of 2002 (e.g. [8]). Correct data for $\mathrm{Ge}, \mathrm{ZnO}$, and $\mathrm{GaN}$ will be analyzed and compared with hydrostatic anvil pressurizations. Several by fitting falsified spherical indentations from peer reviewed publications will be analyzed in Section 4. They are largely prevailing and all of them are worthless in all respects. But we present easy and strict methods to sort them out. Furthermore, the use of unidirectional "Young's modulus" for the simulation of the loading curve to result in the false Johnson equation is incorrect. The data fitting for concurring with it are severe falsification. The therefrom determined "Young's moduli" are dangerously misleading. The enormous trouble when Young's moduli are equalized with indentation moduli has been amply exemplified in [9]. The publication of moduli from "fitted" data [6] adds another aggravation to these 
problems. The unsound theories that emerged from falsified data are, of course, also completely worthless. The purpose of this work is to ask Authors, Peer Reviewers, and Editors to reject papers that use data that are falsified by fitting. Unfortunately, such publications are the basis of certificates for industries, from which these must not deviate. Therefore, numerous false materials' properties create a daily risk for failure upon mechanical stress [5] [10]. Our sorting out techniques below for recent false reports, are clearly developed in this paper. They shall help to repeat the mechanical characterization with true experimental data, when these are unavailable from the recent authors for genuine publications. Falsified results must no longer be used. The below cited and further authors of falsified reports on spherical indentations obtain the possibility to revisit their published data and the connected non-physical theories. The publication of their experimental data for obtaining correct important materials' properties will be highly welcomed. The false theories and the severe risks from incorrect mechanical properties of technical materials in daily life must be removed.

\section{Methods}

The loading data of the materials are taken from the published curves that were enlarged to A4 size. The cone depths were checked with $h_{\text {cone }}=R(1-\sin \beta)$ where $\beta$ is the half angle of the cone and $R$ the sphere radius. When pop-ins was present these were repaired [10]. 20 data points were used and pocket calculator with10 decimals. The results are suitably rounded in text and Table 1 . The calculations according to the Equation (1), Equation (2), and Equation (3) or the arithmetic routines including the energy correction are comprehensibly published in [7]. The $r$-values for the immersed calotte area are easily available by the combined use of $\sin \alpha=(R-h / R)$ and $\cos \alpha=r / R$. The analysis of the spherical loading data used Equation (1) [5] [7]. The indentation work $W_{\text {indent }}$ results from the integrated Formula (2) [7]. The detection of data fittings was with plots of the published data according to the Equations (1) and (3) [11], even though (3) is only valid for pyramidal and conical indentations and would correspond to the false often cited Johnson's equation that must be denoted here as an inequality $F_{\mathrm{Ns}} \neq(4 / 3) h_{\mathrm{s}}^{3 / 2} R^{1 / 2} E^{*}$.

Table 1. Mechanic and energetic data of spherical indentations $(R=4.2 \mu \mathrm{m})$ onto $\mathrm{Ge}, \mathrm{ZnO}$, and $\mathrm{GaN}$ that are reasonable rounded.

\begin{tabular}{ccccccccc}
\hline Material & $\begin{array}{c}F_{\text {Nkink }} \\
(\mathrm{mN})\end{array}$ & $\begin{array}{c}h_{\text {kink }} \\
(\mu \mathrm{m})\end{array}$ & $\begin{array}{c}W_{\text {indent }} \\
(\mathrm{mN} \mu \mathrm{m})\end{array}$ & $\begin{array}{c}W_{\text {applied }} \\
(\mathrm{mN} \mu \mathrm{m})\end{array}$ & full $W_{\text {appl }}$ & $\begin{array}{c}W_{\text {transition }} \\
(\mathrm{mN} \mu \mathrm{m})\end{array}$ & $\begin{array}{c}\text { Areas: flat/cap } \\
\pi r^{2} / 2 \pi R h\end{array}$ & $\begin{array}{c}p_{\text {transition-onset }} \\
\mathrm{mN} / \mu \mathrm{m}^{2}(\mathrm{GPa})\end{array}$ \\
\hline $\mathrm{Ge}^{\mathrm{a})}$ & 10.7029 & 0.1243 & 0.4756 & 6.80929 & 10.9251 & $4.1158^{\mathrm{b})}$ & $3.226 / 3.272$ & $2.331 / 2.298$ \\
$\mathrm{ZnO}$ & 22.3800 & 0.22059 & 2.16661 & 7.54011 & 14.6431 & $7.1030^{\mathrm{c})}$ & $5.6684 / 5.8212$ & $3.7325 / 3.6344$ \\
$\mathrm{ZnO}$ & 56.6290 & 0.51716 & 11,0579 & 15.8916 & 26.4440 & $10.552^{\mathrm{d})}$ & $12,807 / 13.648$ & $4.0438 / 3.7948$ \\
$\mathrm{GaN}$ & 38.8406 & 0.1455 & 2.12467 & 12.3876 & 22.8151 & $10.428^{\mathrm{e})}$ & $3.7731 / 3.8397$ & $10.294 / 10.116$ \\
$\mathrm{GaN}$ & 118.397 & 0.3854 & 24.7506 & 33.8652 & 59.7898 & $25.925^{\mathrm{f}}$ & $9.7038 / 10.171$ & $12.201 / 11.641$ \\
\hline
\end{tabular}

${ }^{\text {a) }}$ Data taken from [7]; ${ }^{\text {b) }}$ up to $50 \mathrm{mN}$; ${ }^{\text {c) }}$ up to $56.6 \mathrm{mN}$; ${ }^{\text {d) }}$ up to $100 \mathrm{mN}$; ${ }^{\text {e) }}$ up to $117.5 \mathrm{mN}$; ${ }^{\text {f) }}$ up to $250 \mathrm{mN}$. 


$$
\begin{gathered}
F_{\mathrm{Ns}}=k_{\mathrm{s}} \pi h_{\mathrm{s}}^{3 / 2}\left(R / h_{\mathrm{s}}-1 / 3\right)+F_{\mathrm{as}} \\
W_{\text {indent }}=2 / 3 \cdot k_{\mathrm{s}} \pi R h_{\mathrm{s}}^{3 / 2}-2 / 15 \cdot k_{\mathrm{s}} \pi R h_{\mathrm{s}}^{5 / 2}+\Delta F_{\mathrm{as}} h_{\mathrm{s}} \\
F_{\mathrm{Npy}}=k_{\mathrm{py}} h_{\mathrm{py}}^{3 / 2}+F_{\text {apy }}
\end{gathered}
$$

The indices in the Equations (1) (2) (3) are $\mathrm{N}$ for normal, s for spherical, a for axis cut when not zero, and py for pyramidal or conical.

The area of the immersed calotte for the onset of the phase-transition pressure calculations is given by its flat surface $\left(\pi r^{2}\right)$ or by its cap surface $(2 \pi R h)$. The radius $r$ is easily obtained by the combination of $\sin \alpha=(R-h) / R$ and $\cos \alpha=R / r$ when looking at the geometric situation for the penetration of the calotte from the sphere with radius $R[5]$.

\section{Results and Discussion}

\subsection{Germanium Spherically Indented}

The spherical indentation analysis of germanium [7] [8] is reported here for comparison with the further examples in Table 1 . Figure 1 provides the basic data from the $F_{\mathrm{N}}$ vs $\pi h^{3 / 2}(R / h-1 / 3)$ plot and by using Equations (1) and (2). It shows the penetration resistances $k_{1}$ and $k_{2}$ as the slopes for the two phases up to $50 \mathrm{mN}$ load.

The phase-transition onset of Figure 1 is at $10.703 \mathrm{mN}$. The energetic data give the indentation work $W_{\text {indent }}=0.4756 \mathrm{mN} \mu \mathrm{m}$ and the transition energy $W_{\text {transition }}=4.1157 \mathrm{mN} \mu \mathrm{m}$, as calculated up to $50 \mathrm{mN}$ load. The transformation pressure is also calculated to give the good correspondence of $2.3 \mathrm{GPa}$ with the anvil pressurizing phase-transition at $2.5 \mathrm{GPa}$. A nevertheless published trial plot in [7] with $F_{\mathrm{N}}$ vs $h^{3 / 2}$ (Equation (3)) for excluding $h^{3 / 2}$ as prescribed by ISO standards and false Johnston's formula for spherical indentations gave a convex plot

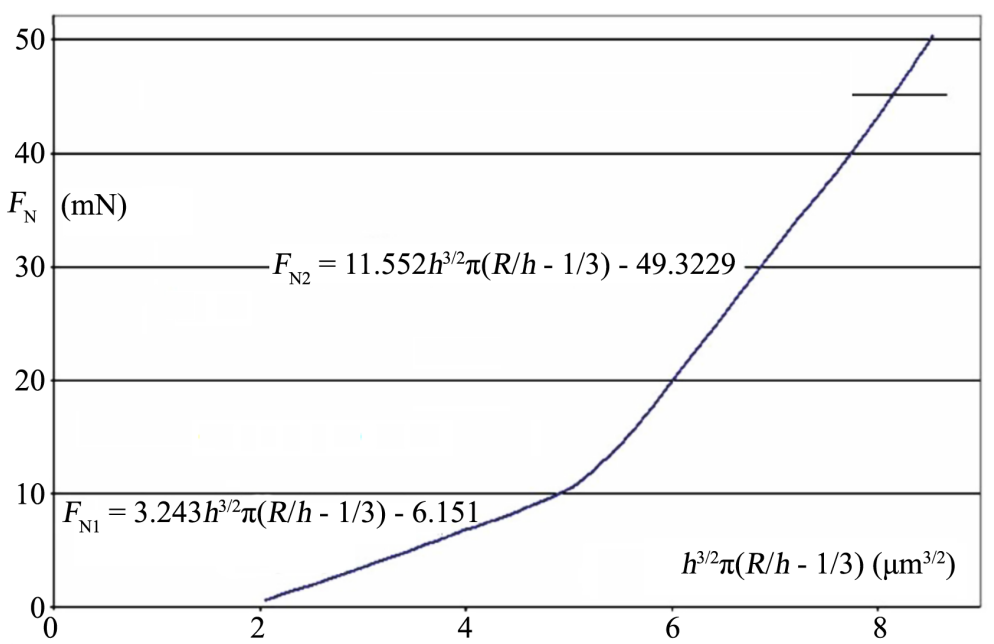

Figure 1. Normal force vs $\pi h^{3 / 2}(R / h-1 / 3)$ plot of a spherical indentation $(R=4.2 \mu \mathrm{m})$ onto germanium, showing the required linearity (regression lines not drawn) and the kink of the Ge-I to Ge-III transition; linear regression equations are inserted; image taken from [7]. 
instead of linearity. A further endothermic phase-transition is already indicated at the end of the second straight line.

\subsection{Zinc Oxide Spherically Indented}

The spherical indentation onto $\mathrm{ZnO}$ with wurtzite structure follows Equation (1) and it reveals two phase-transitions. The analysis had to be performed after repair [10] of the published pop-ins in [12]. The plotted data are in Figure 2, where the included regression data are the basis for the calculations.

The spherical indentation onto $\mathrm{ZnO}$ exhibits two phase-transitions, distinguishing 3 polymorphs in the force range up to $100 \mathrm{mN}$ load, as revealed with the plot by application of Equation (1) to the published original load-depth data. The inserted linear regression equations are the basis for the calculation of the energetic terms and the pressure data in Table 1.

\subsection{GaN Spherically Indented}

The spherical indentation onto a $\mathrm{GaN}$ epilayer $(R=4.2 \mu \mathrm{m})$ was reported in 2002 [13] and the analysis (after pop-in repair [10]) with Equation (1) gives the linear plot with two phase-transitions (three linear branches) as shown in Figure 3. The inserted regression formulas allow for the calculation of the onset forces, the energetic terms, and onset pressures in Table 1.

The more recent spherical indentation onto a single crystal of GaN [14] cannot be compared. Unfortunately, the analysis of these data with Equations (1) and (3) using the techniques for the various further materials in Section 4 shows that these published depth data are fitted according to the ISO14577 standard to concur with the disproved Johnson's formula. These data and conclusions are totally at variance. It would be nice to see the original untreated data.

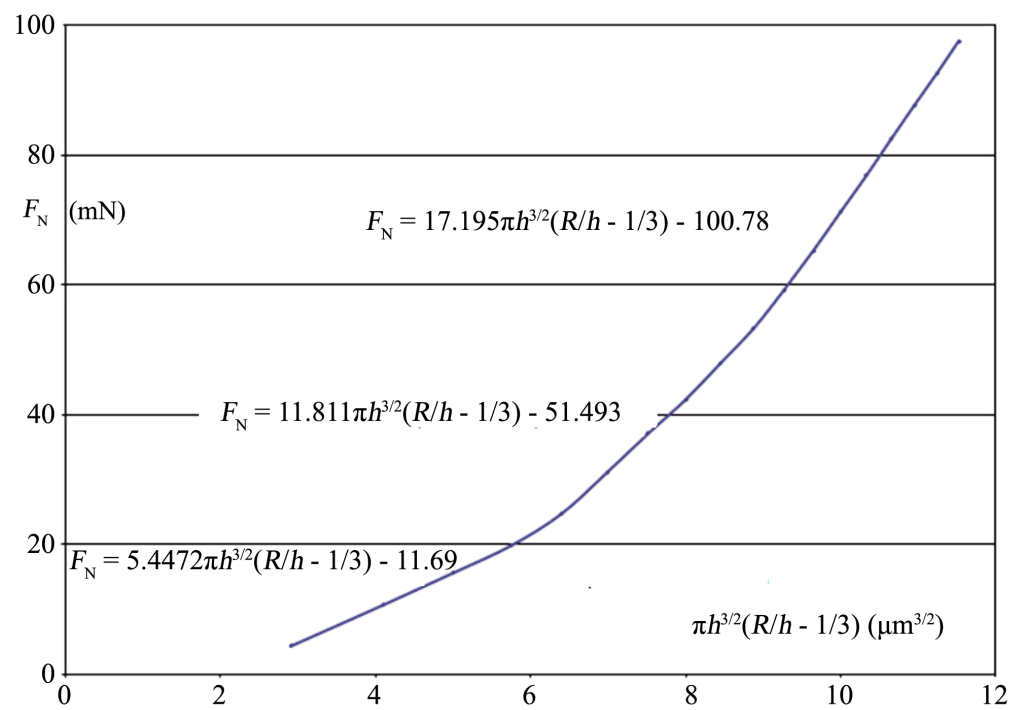

Figure 2. Normal force vs $\pi h^{3 / 2}(R / h-1 / 3)$ plot of a spherical indentation $(R=4.2 \mu \mathrm{m})$ onto $\mathrm{ZnO}$; data taken from Figure 1 in [12] after repair of the pop-ins [10]; linear regression equations are inserted; kink positions in Table 1. 


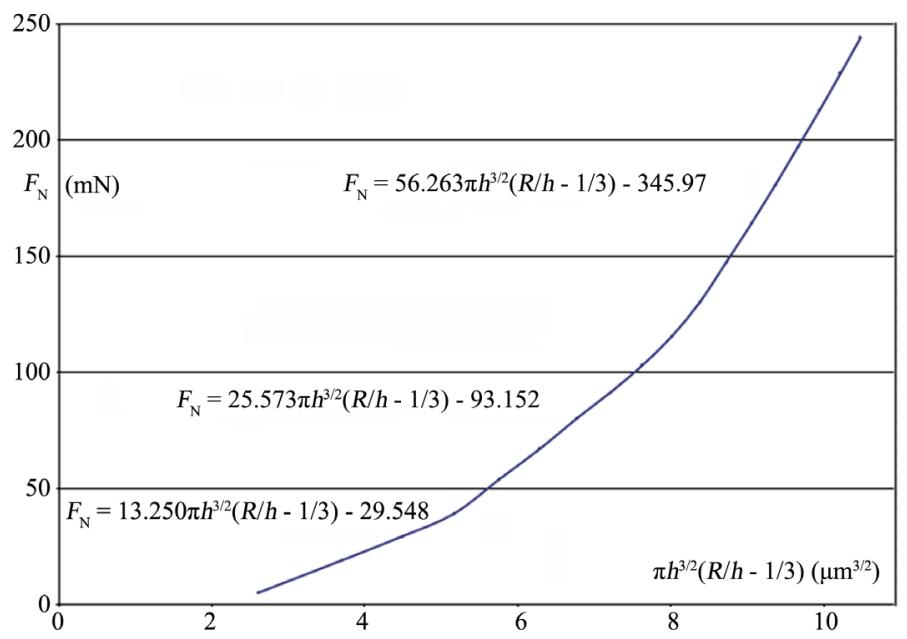

Figure 3. Normal force vs $\pi h^{3 / 2}(R / h-1 / 3)$ plot of a spherical indentation $(R=4.2 \mu \mathrm{m})$ onto $\mathrm{GaN}$; data taken from Figure 1 in [13], showing the required linearity and the kinks for two phase-transitions, ready for the calculation of the results in Table 1; kink positions in Table 1.

\subsection{Comparison of the Results from $\mathrm{Ge}, \mathrm{ZnO}$, and GaN}

The results with Ge, $\mathrm{ZnO}$, and GaN are compared in Table 1 .

These materials cover maximal loads that are $50 \mathrm{mN}$ for $\mathrm{Ge}, 100 \mathrm{mN}$ for $\mathrm{ZnO}$, and $250 \mathrm{mN}$ for $\mathrm{GaN}$. More phase-transition onsets are to be expected at higher loads. The force for the first phase-transition onset describes the sensitivity of the materials for their stability with respect to mechanical interactions. It is equally reflected by the sequence of the penetration resistance values $k_{1}$ (physical hardness) in Figures 1-3. The penetration depth values are not in the same sequence and neither so the first indentation work that are required for reaching the transition onset. But the transition work values are for the first and second transition of $\mathrm{ZnO}$ and $\mathrm{GaN}$ in the same sequence as the $F_{\mathrm{Nkink}}$ values. The data reflect the situation of spherical indentations with the same radius covering one or two phase-transitions per sample. The depths are always very low. The results are calculated from 0 to kink, from kink to kink, and from kink to the maximal force. The transition-energy and the onset pressure values can also be calculated for every force of interest, but they cannot be normalized per force as in the pyramidal case. The energy law requires multiplication of the phase-transition $F_{\text {Nkink }}$ values with $W_{\text {indent }} / W_{\text {applied }}=F_{\text {Nindent }} / F_{\text {Napplied }}$ [7] [15] when only the penetration is addressed, for obeying the energy law. The advantage of experimental spherical indentations is the reliable pressure calculations at the transition onsets. The close similarity of flat surface and cap surface for the low depths is very favorable. It allows the comparison with hydrostatic pressurizing and new insights are therewith achieved.

\subsection{Comparison of the Spherical Indentation with Hydrostatic Pressurizing Data and with Synthesized Polymorphs}

The pressure data of germanium has already been compared with anvil pressure 
as combined with X-ray diffraction date. The low anvil pressure of $2.5 \mathrm{GPa}$ required enormous effort for being detected and was long disregarded, as outlined and discussed in [7]. It corresponds with the onset pressure of $2.3 \mathrm{GPa}$ in Table 1. The present analysis of the spherical indentation is by far easier than anvil experiments but we profit from the X-ray proof for the low-pressure GeI to GeIII phase-transition in a highly rewarding manner. The pressure values for $\mathrm{ZnO}$ in Table 1 up to $100 \mathrm{mN}$ load are not large enough for the B4 to B1 (NaCl-type) transition, because the hydrostatic pressure for that phase-transition are reported to start at $9 \mathrm{GPa}$ [16] or $9.8 \mathrm{GPa}$ [17]. There are numerous reports on theoretically calculated caged $\mathrm{ZnO}$ polymorphs [18] that are not better space-filling than the wurtzite structure (B4) of these materials and need not to be considered here. The theoretical calculations of 7 bulk polymorph structures of $\mathrm{ZnO}$ with respect to expected optical properties is also not helpful, because these lack density predictions [19] and none of these possible structures have been found by anvil pressurizations. The difficulties with resolving low pressure transitions under anvil are already discussed above with germanium. There remain the zinc-blende (=sphalerite) B3 phase and formations of twinned polymorphs. The more highly pressurized of these (onset at $4 \mathrm{GPa}$ ) is most likely the (B3) phase of $\mathrm{ZnO}$ that could already be epitactically grown on (001) of GaAs on a $\mathrm{ZnS}$ substrate at $500^{\circ} \mathrm{C}$. The growth of the film was by metalorganic molecular-beam epitaxy with diethylzinc $+\mathrm{O}_{2}$, "using electron cyclotron resonance plasma source to excite high density oxygen plasma with low-ion energy of $10-20 \mathrm{eV}$ ". The lattice constant of $4.463 \pm 0.015 \AA$ was obtained from the RHEED (high-energy electron diffraction) pattern [20] [21]. The fact that the growing of the film succeeded indicate that the pressure for its formation must be rather low. We can thus confidently claim having detected the first synthesis technique for the bulk $\mathrm{ZnO} \mathrm{B} 3$ polymorph under the diamond calotte cap for further investigation. It is provisionally attributed to the $4 \mathrm{GPa}$ onset pressure. The spacious wurtzite tetrapod with its complicated twinned shape including legs, as obtainable from thermal "vapor deposition on a polymer decorated silicon substrate" [22], must be excluded. The high tendency of $\mathrm{ZnO}$ to form twin structures is known [23]. A $\mathrm{ZnO}$ twin had already been synthesized by pulsed laser deposition [23]. It can also be obtained by electro-deposition on indium doped tin oxide (ITO) [24]. Again, spherical indentation appears to be the easiest synthesis of this species. These attributions must be confirmed by on-site X-ray diffraction at a synchrotron, or spectroscopically. This will include their further characterization. The spherical indentation results of $\mathrm{ZnO}$ reveal that the hydrostatic anvil pressurizing experiments did not resolve these lower pressure phase-transitions. The almost uniform pressure distribution in the low depth spherical indentations is particularly suitable for the suggested investigations.

The GaN B4 phase (wurtzite) transforms upon hydrostatic pressurizing at 47 $\mathrm{GPa}$ into the GaN B1 phase (rock-salt) [25]. Another report found this transition pressure at $37 \mathrm{GPa}$ [26]. These publications do not report on transitions at lower 
pressures that are again not remarked under anvil pressurizing. Thus, the B4 to B3 (zinc-blende $=$ sphalerite) transition pressure was not known. The ab-initio calculations of [27] predict a pressure of $11.45 \mathrm{GPa}$ for the B4 into B3 transition. This value is close to our $12 \mathrm{GPa}$ value in Table 1 and we assign accordingly. Very interesting is our $10 \mathrm{GPa}$ value in Table 1 . When compared to $\mathrm{ZnO}$ this phase-transition occurs at 0.65 times the depth at 1.75 times the force and at 2.75 times the pressure. This may at first glance indicate twinning of $\mathrm{GaN}$, but why should that require so much force and pressure? Another attribution comes to mind: it could be the formation of the rhombohedral phase (R3m) of GaN that has recently be found in the $\mathrm{B} 3$ (zinc-blende, $\mathrm{F} 4-3 \mathrm{~m}$ ) phase of $\mathrm{GaN}$ epilayers, as grown on sapphire by molecular beam epitaxy [28]. This would prevent the twinning by pressurizing upon spherical indentation. Unfortunately, no energetics is available for the rhombohedral phase. The rhombohedral GaN (R3m) forms also via migration enhanced encapsulation growth by encapsulation between silicon and graphene [29]. It is thus easily formed. This would also support our attribution of the first phase-transition onset pressure of $\mathrm{GaN}$ to the rhombohedral polymorph with space group R3m. Clearly, experimental spherical indentation extends the knowledge from hydrostatic anvil pressurizing. Both assignments should be checked by Synchrotron X-ray diffraction together with the now far easier further analyses under the diamond calotte of these elusive and now easily available polymorphs.

\section{Challenge of Simulations and Data-Fitting for Spherical Indentations}

It appears that after publication of the false Johnson's formula requiring an $F_{\mathrm{N}}=4 / 3 \cdot h^{3 / 2} R^{1 / 2} E^{*}$ relation, the ISO standard 14,577 , several textbooks, and publications believed in it (Section 1). A first glance on that Formula (from the beginning in 1985) should have evidenced that it does not take into account the self-evident change of the $R / h$ ratio during penetration. As the experimental data did not concur with the assumed $F_{\mathrm{N}}-h^{3 / 2}$ relation for spheres, Authors did not hesitate to simulate spherical loading curves by using Young's modulus and Poisson's ratio of the material with e.g. the JKR procedures [30] to produce such relation. Thereafter, the experimental depths have been fitted to concur with it by using published "fitting formulas" (e.g. Equation (9) with "fitting parameters" in [6], as is written out in Section 1). That is in fact severe data-treatment. Related other fit-equations might also be in use. But most of the involved scientists stopped with publishing their experimental spherical indentation depths in favor of publishing "fitted depths".

They so avoided the inefficient formula for spheres from [3] and credulously thought to have a simple means for direct determination of the reduced elastic modulus. When doing so they agreed with data manipulation, not recognizing that it was against scientific ethics or practical value. However, anonymous Referees and Editors of books and papers did not stop such data treatments. There were though the important correct publications with Germanium, $\mathrm{ZnO}$, and $\mathrm{GaN}$ 
from 2002 that are cited and successfully analyzed in Section 3. These pioneering papers contain experimental spherical load-depth curves that were apparently neglected, but they rightfully did not agree with Johnson's formula. So, we urge on their revival here.

The "fitting" of depth data is the creation of fake data for making them obey the falsely prescribed $F_{\mathrm{N}}$ vs $h^{3 / 2}$ relation. That relation is however only valid for cones and pyramids [5] [11]. It is more than misleading to unpardonably call the depth values in [6] "experimental data" instead of fitted ones, as in their Figure 4 for a spherical $(R=200$ or $192 \mu \mathrm{m})$ indentation onto PDMS. The exponent analysis according to Equation (3) gave a perfect straight line with a correlation $R^{2}=0.9999$ (no phase-transition) [31]. This was already complained against in [5] (with apology for not expressively having criticized the false $F_{\mathrm{N}} \propto h^{3 / 2}$ relation for spherical indentations in [31]). When the correct $F_{\mathrm{N}} \mathrm{vs} \pi h^{3 / 2}(R / h-1 / 3)$ plot according to Equation (1) is applied to fitted spherical indentations onto materials, one obtains concave curves. That is imaged below for $\mathrm{GaAs}, \mathrm{Al}$, and $\mathrm{Si}$. It is also typical for all the further analyzed materials in this Section 4 (including the fitted curve for GaN from [14] in Section 3.3). These plots are the most compelling proof of data-fittings. When data were fitted to concur with Johnson's formula they must, of course, provide straight lines when plotted according to Equation (3). Such trial plots indicate less sharply that the fitting had not completely wiped out any phase-transition unsteadiness. But one must not use such plots of manipulated data for phase-transition characterizing. It would be completely misleading to do so: we show with all of the analyzed examples in this Section 4 that one would always falsely claim exothermic behaviors while the phase-transitions are in all tried cases endothermic.

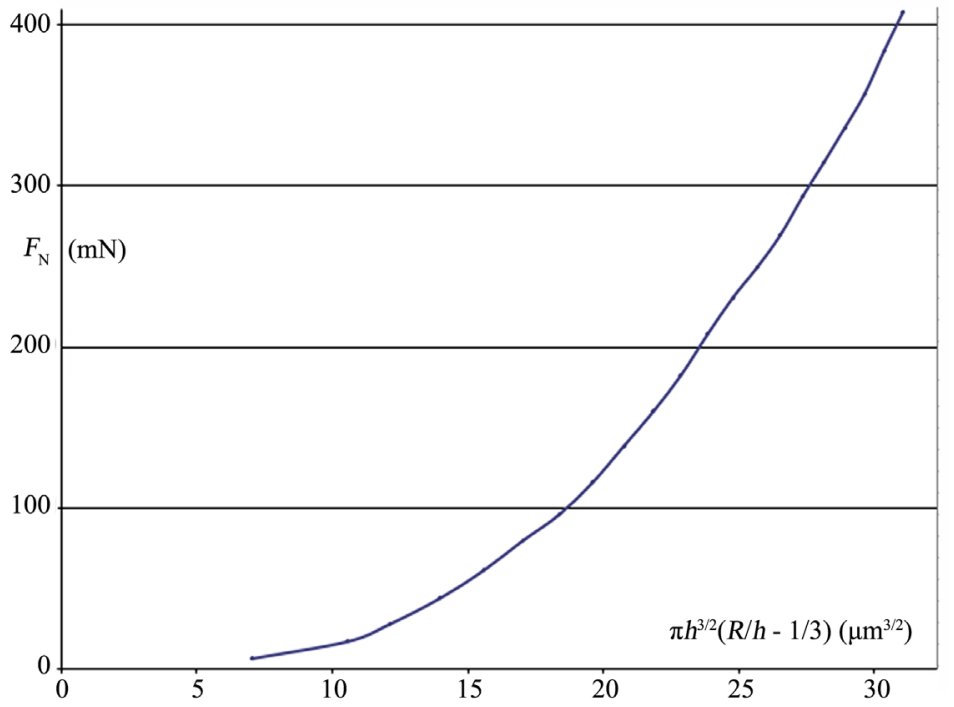

Figure 4. Plot according to Equation (1) for spherical indentations of the published clearly fitted data as taken from [32] for a spherical indentation with $R=10 \mu \mathrm{m}$ onto GaAs, proving the data fitting for concurrence with the disproved Johnson's equation, as no straight line ensued. 
It appears that most published spherical indentations were "fitted" to obey the incorrect Johnson's formula with its false promise to obtain "Young's moduli" values that are however incorrect fake values, not to speak of the fact that Young's moduli are unidirectional moduli. Importantly, we can easily distinguish valid from fitted invalid spherical indentation reports by simply checking their loading curves with plots according to the Equations (1) and (3).

We do not further deal here with the details of the JKR simulations [30] and the data-fitting techniques concerning the spherical indentations, because that is unscientifically false. Such data treating is dangerous and against scientific ethics. The falsified outcome will now be further exemplified with some unbelievably manipulated published loading curves of varied types. It is hoped that this somehow difficult task will help to positively develop this important field of materials' analyses.

\subsection{Gallium Arsenide "Spherically" and Pyramidally Indented}

The spherical indentation $(R=10 \mu \mathrm{m})$ of GaAs in [32] does not follow the equation for spherical indentations (1) and the Authors cited paper [4]. The analysis of the published loading curve-after repair of the "pop-in" in their Figure 1(a) - with Equation (1) for spheres does not give a straight line with Equation (1), but the concave curve of Figure 4. This indicates the belief of the authors in Johnson's formula from 1985 and the application of a fitting procedure to the original loading data to concur with such formula.

Conversely, the application of Equation (3) for cones and pyramids as falsely claimed by Johnson to the data of [32] leads, after a short initial effect, to two straight lines, the first steeper as the second by forming a kink. This is shown in Figure 5. The disproved Johnson's formula requires, of course, linearity with the

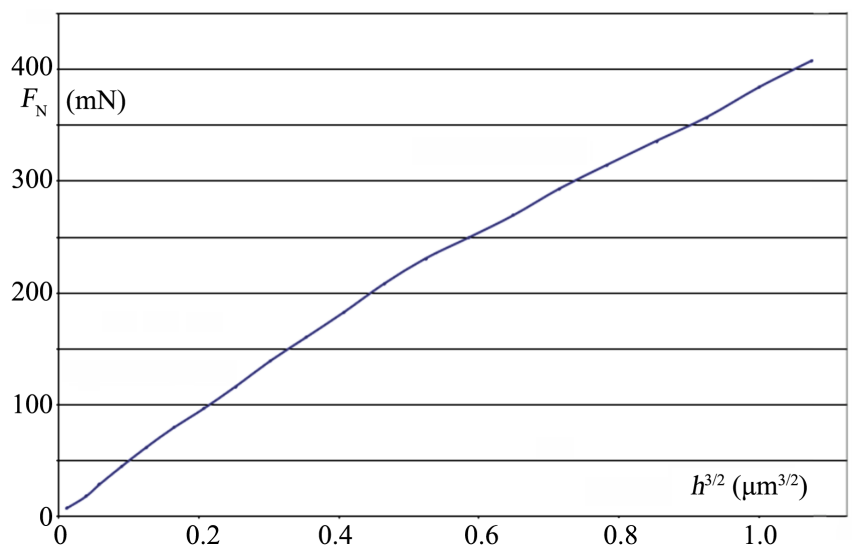

Figure 5. Trial plot with the data as in Figure 4 from the spherical indentation $(R=10$ $\mu \mathrm{m})$ onto GaAs (100) with the clearly fitted data as taken from [32], showing after an initial effect two straight lines with trial regression lines of $F_{\mathrm{N} 1}=433.6 h^{3 / 2}+6.6$ and $F_{\mathrm{N} 2}=$ $325 h^{3 / 2}+57.9 \mathrm{mN}$ that would falsely simulate an exothermic transition event with an onset at $213 \mathrm{mN}$ and a here provisionally calculated impossible transition energy per $\mathrm{mN}$ of $-0.101 \mathrm{mN} \mu \mathrm{m} / \mathrm{mN}$. This exothermicity is dangerously in error and the slopes in Figure 5 have no physical meaning. 
exponent $3 / 2$ on $h$ for fitted spherical indentations. However, the putative exothermic event does not represent the endothermic phase-transitions of GaAs, and also the slopes are simulation and iteration artefacts without any value.

This data check proved the already complained data fitting. It appeared therefore necessary to compare the values in the caption of Figure 5 with the ones from the correct analysis of Berkovich indention loading curves onto GaAs. These are taken from Figure 1 in [33] at low penetration (up to $4.5 \mathrm{mN}$ ) and from Figure 3(a) of [34] at high penetration (up to $600 \mathrm{mN}$ ). These genuine experimental curves were analyzed to yield kink points for endothermic phase-transitions at 2.517 for loads up to $5 \mathrm{mN}$ and $218 \mathrm{mN}$ for loads up to $600 \mathrm{mN}$. The first of these with onset at $2.517 \mathrm{mN}$ is not resolved at this loading range. The second of these loads in Figure 6 starts pretty close to the one in Figure 5, but the calculated mechanical data are principally different. The second branch is steeper than the first one, indicating the endothermic phase-transition with the onset (kink position) at $218 \mathrm{mN}$ load and $1.40 \mu \mathrm{m}$ depth. The normalized Berkovich indentation transition-energy with onset at $218 \mathrm{mN}$ is endothermic at +0.161 $\mathrm{mN} \mu \mathrm{m} / \mathrm{mN}$ [this work], as deduced with Equation (3) for cones and pyramids and its integration in [7] [11]. Thus, the spherical indentation with $R=10 \mu \mathrm{m}$ onto GaAs is a misleading fitting artifact showing again the data treatment in [32]. The importance of the argument deserves the printing of the Berkovich indentation analysis of the experimental result from [34] in Figure 6.

Figure 6 where Equation (3) is correct for the pyramidal indentations and the Kaupp-plot [11] proves undoubtedly that the phase-transitions of GaAs under load are endothermic.

As we present strong arguments, we must check whether further fitted spherical indentation exhibit the corresponding behavior.

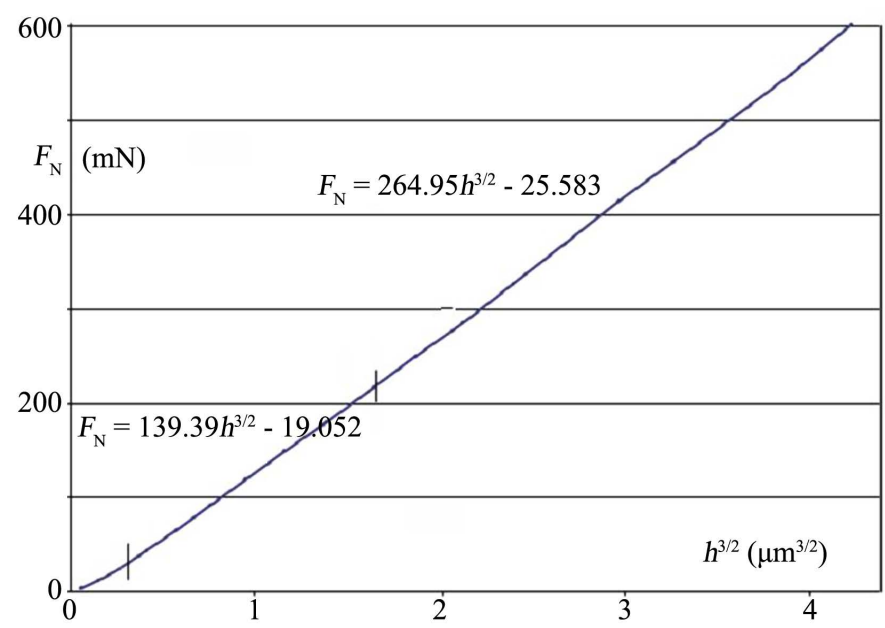

Figure 6. Analysis with the Kaupp-plot (Equation (3) of the Berkovich indentation onto GaAs (data taken from Figure 3(a) in [34]) showing after an initial unresolved part two linear branches with the inserted regression equations that both correlate with $\mathrm{R}^{2}=$ 0.9999; the slopes of the pyramidal indentation in Figure 6 are the penetration resistance values of the two polymorphs. 


\subsection{Aluminum "Spherically" Indented}

The analysis of the spherical indentation onto aluminum [35] reveals a similar outcome as with GaAs. The sphero-conical indenters are precisely described with a cone half angle of $45^{\circ}$ and nominal radii of $10 \mu \mathrm{m}$ and $5 \mu \mathrm{m}$. Scanning electron microscopic images indicated "well formed" radii of 8.5 and $5 \mu \mathrm{m}$ down to depths of 2.5 and $1.5 \mu \mathrm{m}$, respectively. The nominal radius of $10 \mu \mathrm{m}$ corresponds to $h_{\text {cone }}=2.93 \mu \mathrm{m}$. This is considerably larger than the maximal depth of $<1 \mu \mathrm{m}$ ) for the indentation data of pure Al. Again, the analysis with Equation (1) for spheres does not give a straight line but the concave curve of Figure 7, which clearly indicates a data fitting for concurring with Johnson's formula and unfortunately ISO standard.

The trial plot with Equation (3) to the spherical indentation in Figure 8, using the same fitted data as for Figure 7 is linear with after the extended initial effect two straight lines. These simulate an exothermic event, because the second branch has the lower slope. This is the false and dangerous result of the fitting error as above with GaAs (Figure 5): the phase transition of aluminum under load is endothermic, as was already shown with Berkovich indentations onto aluminum in [31].

Again, the calculations of elastic moduli according to false Johnson's formula and its discussion are useless and misleading. The data fitting is again safely confirmed with Figure 7 and Figure 8. The previous branch is again steeper than the following one, simulating a false exothermic event. The known phase-transition of aluminium upon Berkovich indention has the endothermic phase-transition onset at close to $40 \mathrm{mN}$ load (two different sources) [31]. The similarity with the above GaAs case repeats the falsifications by the fittings. Again, the falsified data for an $h^{3 / 2}$ loading parabola retain only the information that there must be a phase-transition at a similar force, as characterized with a Berkovich indentation.

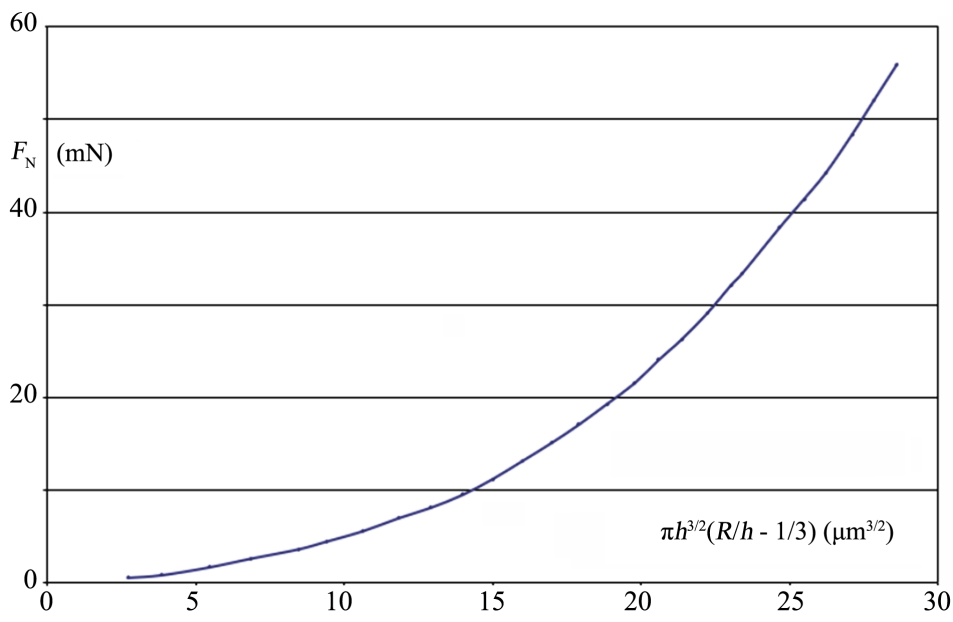

Figure 7. Analysis of the published fitted data from the spherical indentation with a nominal radius of $10 \mu \mathrm{m}$ onto pure aluminum according to Equation (1); data are taken from the upper data points of the multiple partial loading Figure 12(b) in [35]; the concave bending does not agree with Equation (1) and proves the data-manipulation. 


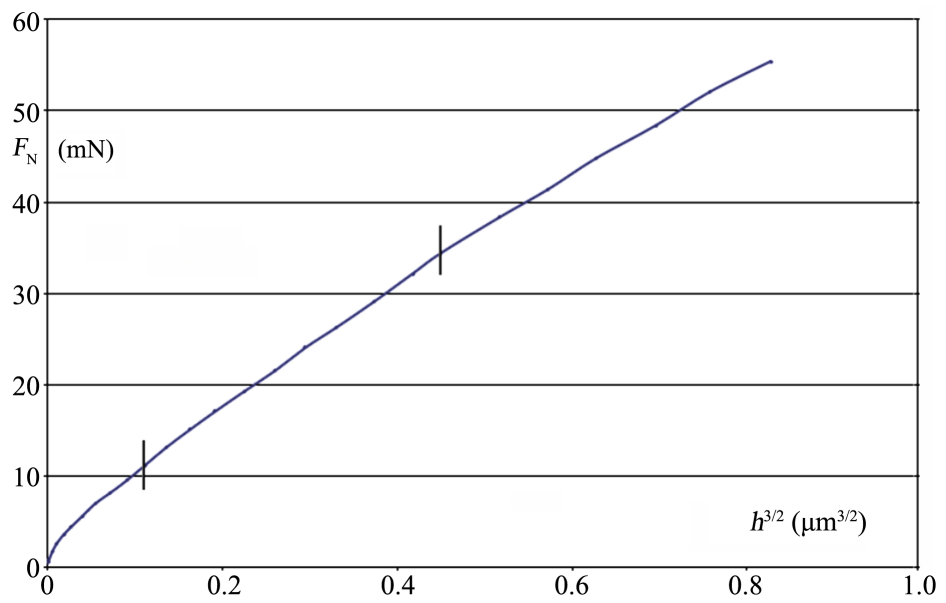

Figure 8. Trial Kaupp-plot according to Equation (3) for the spherical indentation onto aluminium substantiating the undue "fitting" of the original experimental data; this plot appears as if it were the result of a conical or pyramidal indentation instead of a spherical one with $R=10 \mu \mathrm{m}$; after the initial effect (oxide and polishing) two extended straight branches with unsteadiness at about $33 \mathrm{mN}$ loads that would simulate an exothermic event, but not the endothermic phase-transitions of aluminium; the "averaged" data crosses are taken from Figure 12(b) in [35]; the slopes in Figure 8 have no physical meaning.

Data fitting destroys the value of spherical indentation and excludes any use of them. "Fitted" data points must not be told or suggested as being "experimental" ones.

\subsection{Silicon "Spherically" Indented}

Spherical indentations $(R=8.5 \mu \mathrm{m})$ of silicon were published in [36]. Photos of a sphere and a description of their indenter setup as " $A$ ll of the force-displacement measurements were made on a UMIS-2000 instrument", and also the copious description how "The indentations were carried out" are indicating that they might have been without data-fitting. Only the cone angle of the conoidal indenter was not disclosed. However, the authors relied in their text on the incorrect Johnson's formula with the impossible $F_{\mathrm{N}}$ vs $h^{3 / 2}$ relation for spherical indentations. This must again be severely challenged. Our analysis of the published "experimental" data pair crosses from their Figure 4(a) (similarly in the further images) give again no straight line when the Equation (1) for spheres is applied to the published data. The concave curve in Figure 9 is obtained instead.

The data-fitting is again additionally secured with the trial Kaupp-plot ( $F_{\mathrm{N}}$ vs $h^{3 / 2}$ ) in Figure 10, using the so called "observed" but in reality, fitted loading curve data pairs (the data crosses next to the simulated curve in [36]). This second proof is evident by the linearity with exothermic unsteadiness at about 30 $\mathrm{mN}$ and very pronouncedly at $80 \mathrm{mN}$ load.

As shown with GaAs and aluminium, the residual information of exothermic unsteadiness tells only that phase-transitions will be found by Berkovich indentation. The steepness of the preceding lines in Figure 10 is again higher than 


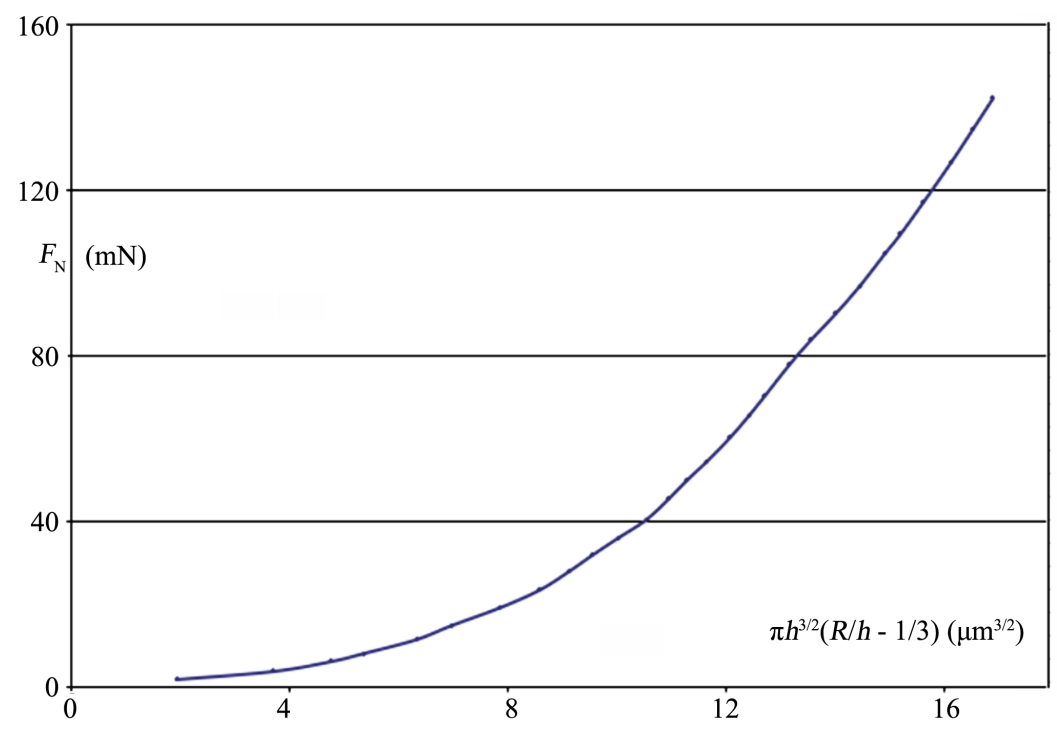

Figure 9. Plot of the spherical indentation $(R=8.5 \mu \mathrm{m})$ onto silicon (100) according to Equation (1); the concave form instead of the required linearity proves the data-manipulation in Figure 4(a) of [36], from where these were taken.

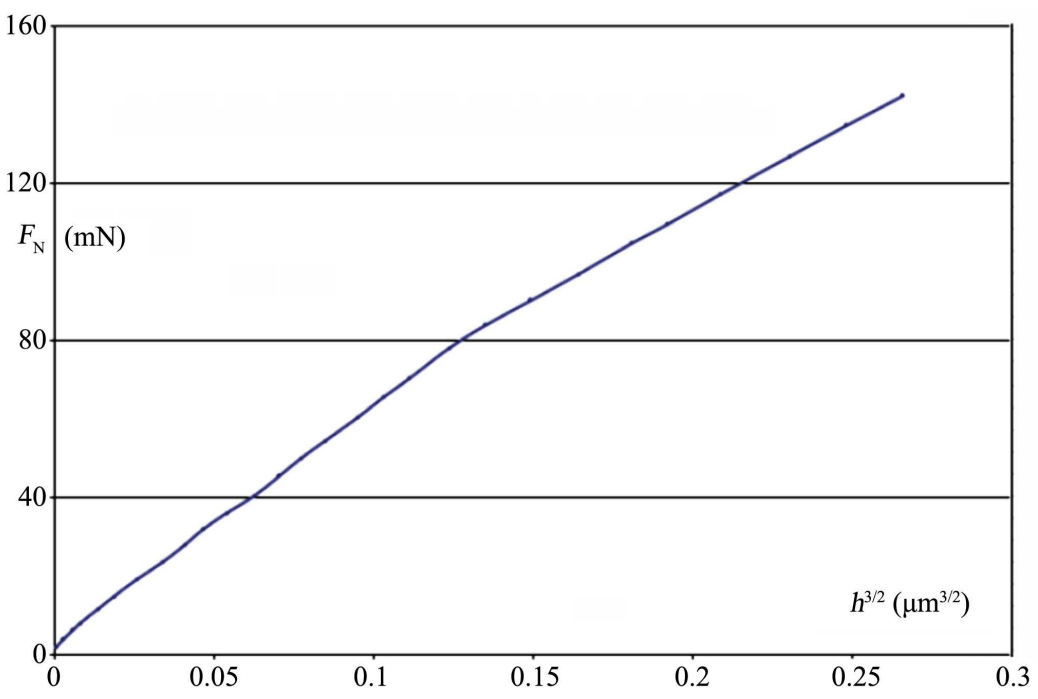

Figure 10. Trial plot of the spherical indentation $(R=8.5 \mu \mathrm{m})$ onto silicon (100) according to Equation (3), showing linearity with kinks at about 30 and $80 \mathrm{mN}$ loads that mimic exothermic event, whereas the phase-transitions at such forces are endothermic; the lower force onset requires a ruler; the artificial slopes in Figure 10 have no physical meaning.

that of the following ones. This seems to be indeed typical for the undue fitting procedure. The genuine silicon phase-transitions are all endothermic: the Berkovich indentation onsets of $\mathrm{Si}(100)$ at 4, 15 and 25 (data taken from [37]) or 29 and $81 \mathrm{mN}$ (data taken from [38]) were analyzed in [39]). They reveal endothermic phase-transitions.

Unfortunately, the more recent spherical indentation with $R=5 \mu \mathrm{m}$ of [40] also used Johnson's formula and the Authors do not disclose their cone angle. We therefore do not discuss it here. 


\subsection{Silicon Carbide "Spherically" Indented}

Datye et al. in [41] published spherical indentation data of silicon carbide ( $\mathrm{SiC})$. They used their SiC-N brand "that is similar to (0001) of the single crystap". With their sphere radii of $25 \mu \mathrm{m}$ and $7.5 \mu \mathrm{m}$ they reached fully elastic or elastic and plastic indentations, respectively. The data were "fitted" to "Hertz spherical contact solution", which means: the disproved Johnson's equation was again the fitting target. These published load-depth curves with fitted depths do again not follow the Equation (1) for spherical indentations. They give the concave curve when tested with Equation (1) and they analyze linear with the trial Kaupp-plot (that is only valid for pyramids and cones) according to Equation (3) without unsteadiness up to $475 \mathrm{mN}$ load. After short initial effect, the simulated slopes of $1030(R=7.5 \mu \mathrm{m}) \mathrm{mN} / \mu \mathrm{m}^{3 / 2}$ or $3742(R=25 \mu \mathrm{m}) \mathrm{mN} / \mu \mathrm{m}^{3 / 2}$ are obtained with correlation coefficients of 0.9997 or 0.9999 , respectively. These do however not describe any materials' property, but only reflect the fitting efficiency. We nevertheless determined these slopes despite the data-fitting, for provisionally checking the influence of the tip radius influence. Interestingly, despite the fitting treatment of the depths, the ratio of these slopes (3.7) is similar to the ratio of the radii (3.3). It should be further studied whether such a relation holds also for spherical indentations with untreated experimental depth data. The mayor errors of the simulating procedure appear to be the modulus $E^{*}$ as calculated with the false Johnson formula.

The phase-transition pressures of $\mathrm{SiC}$ have been calculated to 102 and $105 \mathrm{GPa}$ (hexagonal $6 \mathrm{H}$ to $1 \mathrm{~B}$ ) or (cubic $3 \mathrm{C}$ to $1 \mathrm{~B}=$ sodium chloride) phase, respectively, and the experimental shock data have them at about $100 \mathrm{GPa}$ [42]. This is far from being reached with the maximal force of $500 \mathrm{mN}$ in [41].

There seems to be the same data fitting techniques in all of the here analyzed cases, but we still need further analyses with a crystalline oxide.

\subsection{Magnesium Oxide "Spherically" Indented}

The authors of [43] used a polished and rinsed (001) surface of $\mathrm{MgO}$ for a "spherical indenter in diamond" with an iterated radius of $9.5 \mu \mathrm{m}$. Their published Figure 1(c) in [43] is completely reversible up to $300 \mathrm{mN}$ load and $0.4 \mu \mathrm{m}$ depths. The data fitting is clearly revealed by their reference to [4] and again by the concave plot that results by application of Equation (1) to the published force-depth curve. We need thus not deal any further with this report.

\subsection{Steel "Spherically" Indented}

For rounding up our knowledge of the falsifying effects of data-fitting spherical indentations we also need the analysis of a technical multi-component material. A spherical indentation onto a standard microhardness steel block (500 HV30; $H / E=0.04$ ), using a sphero-conical tip with radius of $7.2 \mu \mathrm{m}$ [44] and cone half angle of $45^{\circ}$ [35] (we calculate $h_{\text {cone }}=2.11 \mu \mathrm{m}$ ) appeared appropriate. Actually, the nominal radius of $5 \mu \mathrm{m} \pm 6.6 \mathrm{~nm}$ (we calculate $h_{\text {cone }}=1.46 \mu \mathrm{m}$ ) was in- 
creased by a "well-fitting simulation" to $7.2 \mu \mathrm{m}$. And the "nominal values of 210 GPa and 0.3 were assumed for Young's modulus and Poisson's ratio in all simulations". The load-depth data were taken from Figure 5(a) in [44]. The application of Equation (1) for spherical indentation is valid for every tip radius as long as the $h_{\text {cone }}$ value is not surpassed. But the depth values for a certain force are strongly dependent on the tip radius (cf. Section 4.4.). Again, concave curves (not shown here) but not straight lines are obtained both for nominal $5 \mu \mathrm{m}$ or iterated $7.2 \mu \mathrm{m}$ radius. These analyses tell that our already multiply complained data-fitting was again performed in [44]. Figure 11 ensued, when the Kaupp plot according to Equation (3) was applied to the clearly fitted loading data. It exhibits three linear branches that simulate two unsteadiness points both with misleading exothermic behavior. Neither the slopes nor the exothermicities are usable. The known phase-transitions of steels and iron are endothermic. A numerical comparison with their onset forces would require a Berkovich indentation of this particular multi-component steel. It should be stressed that the radius $R$ must be measured but never be simulated. It plays an important role for the outcome of experimental spherical indentations.

The unsteadiness onsets in Figure 11 cannot be termed phase-transition values, as they would falsely claim "exothermic" behavior and the slopes are worthless. They are equally false as in the cases for GaAs, Al, and Si. Despite the obvious errors of data-fitting for obeying ISO 14577 standards, the authors of [44] relied on the false Johnson formula for "Young's modulus" determinations from a simulated loading curve. These are nothing else than faked results.

Very strange is the publication of Figure 3 in [44]. The tip radius had been shifted from $50 \mu \mathrm{m} \pm 1.4 \mathrm{~nm}$ to $115 \mu \mathrm{m}$, because the data could "only be well fitted" to the simulated Johnson loading curve with $R=115 \mu \mathrm{m}$. Such behavior is

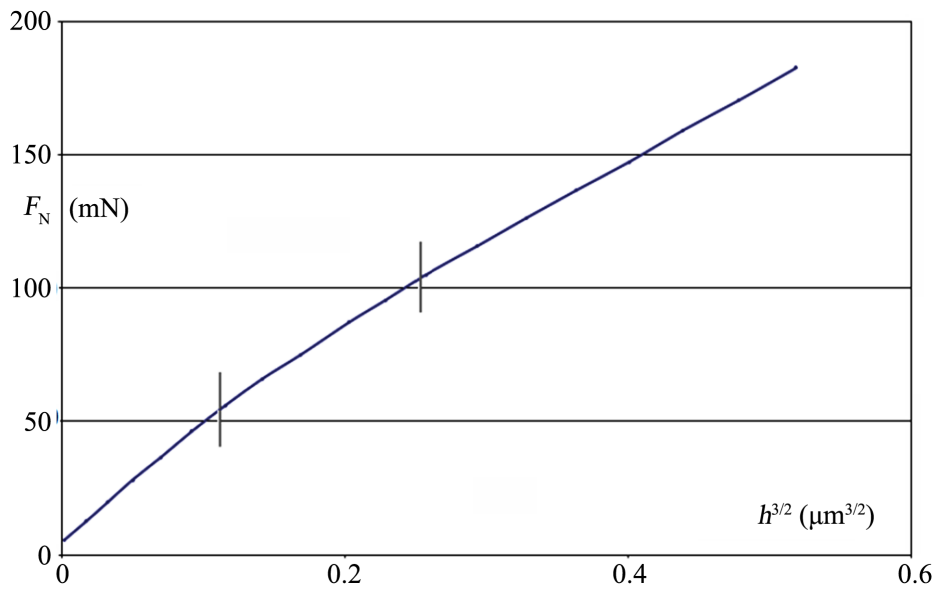

Figure 11. Trial plot according to Equation (3) for the spherical indentation (iterated $R=$ $7.2 \mu \mathrm{m}$ ) onto the steel with $H / E=0.04$, as taken from Figure 5(a) in [44] by using their fitted data point crosses; the force vs depth ${ }^{3 / 2}$ plot-only valid for conical or pyramidal indentations-shows three linear branches simulating two exothermic events due to the data-manipulations, while phase-transitions of steels are endothermic; the slopes in Figure 11 have no physical meaning. 
absurd. The Authors of [44] did not at all recognize that the course of a spherical indentation strongly depends on the radius $R$. They tried to justify their shifting with the inconceivable claim that "a slight flattening of the spherical shape over the $4.5 \mu \mathrm{m}$ radius contact region, arising from as little as $0.11 \mu \mathrm{m}$ at the center, is sufficient to produce an increase in spherical radius of this amount" (from $R=$ $50 \mu \mathrm{m} \pm 1.4 \mathrm{~nm}$ into $R=115 \mu \mathrm{m}$ !). Tip radii are mechanical data that cannot be shifted by iterations "as necessary". While all of that already proves the multiple data treatment, we nevertheless checked the fitted data with our test methods. The application of Equation (1) give the differently sized concave curves (not imaged here) for the data pairs with $R=115 \mu \mathrm{m}$ and for the simulated curve with nominal $R=50 \mu \mathrm{m} \pm 1.4 \mathrm{~nm}$. This confirms the data fitting, as in all of the other tested cases in Section 4.

Furthermore, both simulated curves for the spherical indentation "of a steel standard hardness block (900 HV30 nominal' with $H / E=0.4$ in Figure 3 of [44]) give linearity when trial plotted according to Equation (3). The simulated $R=50$ $\mu \mathrm{m}$ radius curve gives an exothermic unsteadiness at about $100 \mathrm{mN}$ and 0.150 $\mu \mathrm{m}$ (not imaged here) with our calculated pressure of $p=2.11 \mathrm{GPa}$. Conversely, the simulated $R=115 \mu \mathrm{m}$ curve in [44] gives the single straight line in Figure 12 again with the maximal force at $200 \mathrm{mN}$ from the first to the last data point without any unsteadiness. This only tells the high fitting precision that is obtained with the published equations in e.g. [6] (as written down in Section 1). Our calculated pressure in Figure 12 at its end with $200 \mathrm{mN}$ load gives $p=1.58$ GPa. This clearly misses the unsteadiness at $p=2.11 \mathrm{GPa}$ with $R=50 \mu \mathrm{m}$, as such a high pressure is not reached with a more than twice as high radius $R$. It stresses however the enormous influence of the tip radius. In the present case one must be alerted of not mixing up the fitted spherical indentation (that is totally

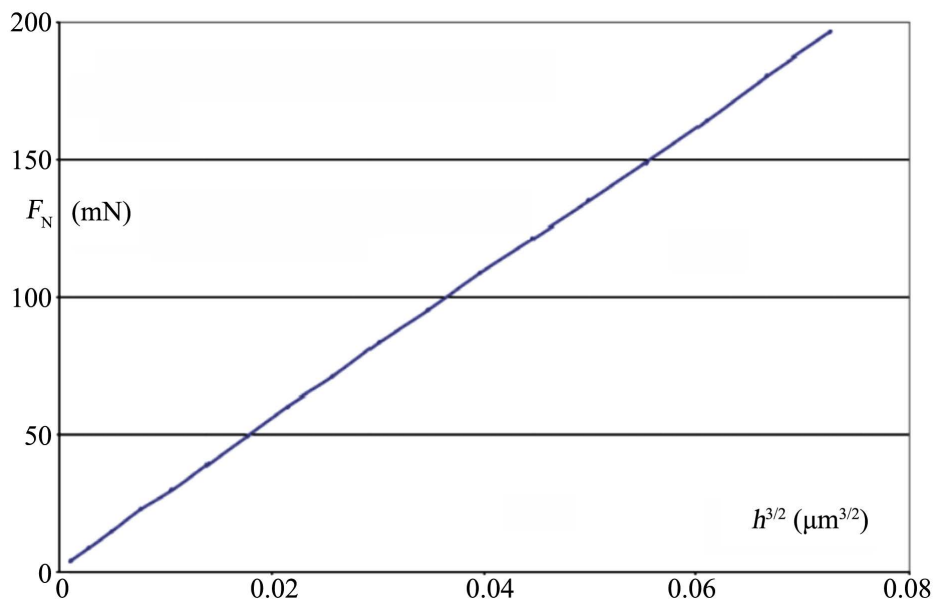

Figure 12. Trial Kaupp-plot according to Equation (3) for the spherical indentation (iterated $R=115 \mu \mathrm{m}$ ) onto a steel standard hardness block (900 HV30 H/E= 0.4); the clearly fitted "data" are taken from Figure 3 in [44]; it shows a perfect straight line without unsteadiness, as the fitted spherical indentations falsely require an $F_{\mathrm{N}}$ vs $h^{3 / 2}$ relation; the onset pressure of the unsteadiness is not reached; the slope in Figure 12 has no physical meaning. 
worthless) with a pyramidal or conical indentation that would give a totally different slope (yet unknown for steel $900 H / E 0.4$ ). It appears rather strange that the paper [44] could pass the Reviewers and Editors for its publication in the Journal of Materials Research. Fortunately, our mathematically sound analyses are now able to detect the invalid simulations, fittings, and iterations, by using Equation (1).

The plot in Figure 12 again underlines the unique power and necessity of checking publication data from spherical indentations with the correctly deduced Formula (1) in [5] and [7]. It reveals: both of the manipulated data in Figure 3 of [44] $(R=115 \mu \mathrm{m}$ or of nominal $50 \mu \mathrm{m})$ are totally worthless due to various simulations, iterations, and fittings for concurring with the disproved Johnson equation that does not take care of the depth-dependent $R / h$ ratio during the penetration. Even worse, the influence of the tip radius to the applied pressure was not acknowledged when nominal tip radii were changed by iterations (5 into 7.2 or 50 into $115 \mu \mathrm{m}$ ).

A very recent report deals with the spherical indentation of several steels with a ball of radius $250 \mu \mathrm{m}$, in e.g. Figure 10 of [45]. The Authors used the techniques of [35] and published several "experimental" indentation curves. We analyzed the one for DC01 steel. The test with Formula (1) for spheres gives the concave curve (not imaged here) corresponding to the ones that we always obtained when the spherical indentation data were fitted. This paper [45] covers high loads up to almost $200 \mathrm{~N}$. The trial test with Equation (3) for conical or pyramidal indentations gives three linear branches at very high load with two unsteadiness points, simulating again worthless exothermic behavior. This $F_{\mathrm{N}}$ vs $h^{3 / 2}$ plot in Figure 13 proves that the simulation, iteration, and fitting techniques from 1993 [44] and 1995 [35] are unfortunately still in active use.

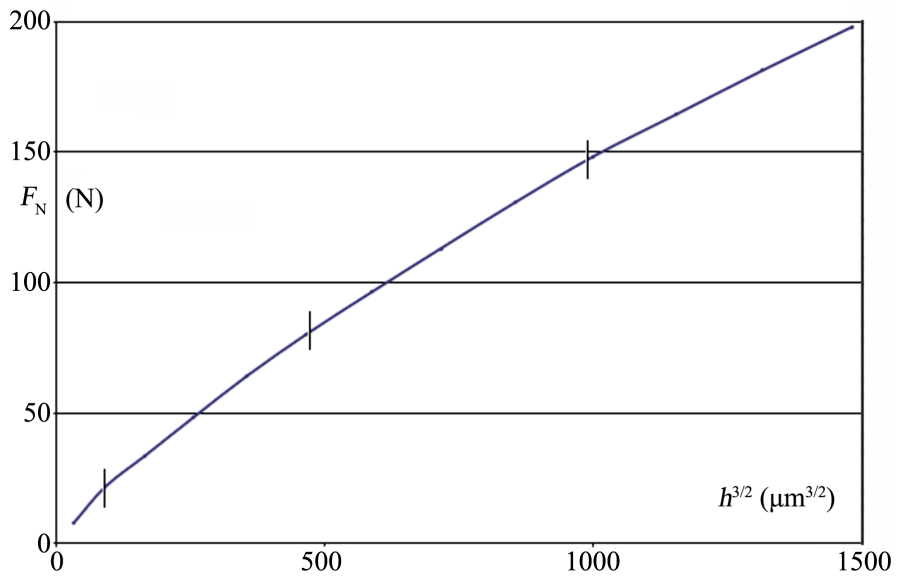

Figure 13. Trial Kaupp-plot according to Equation (3) for the high-load spherical indentation ( $R$ approximately $250 \mu \mathrm{m}$ ) onto steel DC 01 , using the fitted data as taken from Figure 10 in [45]; it presents after the unresolved initial effect two unsteadiness kink-points that would misleadingly indicate exothermic events; the reasons are the undue simulation, iteration, and data-managing techniques for complying with the incorrect Johnson's equation and with the present ISO-14577 standard; the slopes in Figure 13 have no physical meaning. 


\section{Conclusions}

A prerequisite for the analysis of spherical indentations is the use of the correctly deduced force-depth relation (Equation (1) that takes into account that the $R / h$ ratio changes strongly during the penetration. Equation (1) describes experimental (not fitted) spherical indentation loading curves. Unfortunately, data-treatment with simulations and fittings are still (2020) used by ISO 14577 prescriptions with the false Johnson Formula (here as an inequation $\left.F_{\mathrm{N}} \neq(4 / 3) h^{3 / 2} R^{1 / 2} E^{*}\right)$ that does not care for the $R / h$ changes. Typical loading curves from spherical indentations with (untreated) experimental data for $\mathrm{Ge}$, $\mathrm{ZnO}$, and GaN are successfully analyzed. The unprecedented results demonstrate the unexpected wealth of spherical indentations. The plot of the experimental data according to Equation (1) is linear with kinks at the phase-transition onset points (one, or two within the loading ranges). In addition to the onset force and onset pressure one obtains the phase-transition energy. These values are of great value for the rating of the materials' compliances and for avoiding phase-transitions with their dangerous polymorph interfaces by overloading. These are mayor advances of experimental spherical indentations. The transition onset pressures can be compared with available anvil pressure onsets, because we are close to hydrostatic conditions. In the case of germanium, our calculated onset pressure favorably supports the results of the anvil experiment that had formerly been questioned. It turns out that low-pressure phase-transitions under anvil pressurizing are either not resolved, or too rapidly overrun, or simply overlooked. Our detected polymorphs under the sphere calotte are also reasonably attributed. The most favorable uses of experimental spherical indentations are the expansion of the mechanical characterization of materials and the controlled synthesis of the various polymorphs that is much easier than by any other technique. The polymorphs are located at a most favorable site under the sphere calotte cap, clean and next to their preceding less dense polymorph. That opens new horizons for their structure elucidation by X-ray diffraction and spectroscopy. This should become the method of choice for the characterization of other solid materials with their polymorphs.

Any trust in the historical concepts and formulas is unsuitable and dangerous. Despite their apparently general use, one must strongly reject the false Johnson formula and all connected false theories that neglect the $R / h$ dependency. It should have been seen before by Authors, Reviewers and Editors when looking at the abounding printed circles in most of the relevant papers. There is no excuse when black-box routines in their instruments might have automatically simulated, iterated, and fitted. Furthermore, the technical users who apply the JKR technique for the evaluation of adhesion properties (cf [6]) should also be alerted for checking, whether they use experimental or falsified force-depth related quantities for obtaining reasonable results.

We finally state that valid reported spherical indentations are very useful for complementing the highly demanding and less sensitive hydrostatic pressurizing 
experiments. They reveal also the lower-force phase-transition pressures that might have been hydrostatically overlooked under the anvil. It will be possible now to recognize and stop the widespread data falsifying techniques not only for regaining the scientific reputation in the field of indentations. Peer Reviewers must no longer support data falsifying fake papers. It is not enough when historical authors are cited with their paper titles, but without referring to their antiquated content, or when black-box manipulations produce exact coherency with erroneous equations. The risk of false technical materials' properties will be removed by the sorting out of falsified data and by urgent repetition of the corresponding indentations, if the original experimental data are no longer available for revised publication. The various new possibilities with experimental spherical indentations provide all of the further important characteristics of phase-transitions. They open new horizons for creation and structural characterization of yet unknown polymorphs of materials. For technically used materials they tell how to avoid dangerous cracking, originating from polymorph interfaces, which often continue to disastrous crashes [5] [10] in daily life upon overloading. General help is required for reaching physically sound indentation analyses. Applications for the urgent replacement of the incorrect loading equations with the physical and mathematical correct formulas (1) and (3) have been filed by the author for a hopefully soon coming revision of ISO 14577.

\section{Conflicts of Interest}

The author declares no conflicts of interest regarding the publication of this paper.

\section{References}

[1] Hertz, H. (1882) Über die Berührung fester elastischer Körper. Journal für die reine und angewandte Mathematik, 92, 156-171. Translated Work: On the Contact of Elastic Solids, \#5 in Miscellaneous Papers by H. Hertz, Ed. P. Lenard. Physics Publisher London: New York Macmillan and Co., New York, 1896, 146-162. https://archive.org/details/cu31924012500306 https://doi.org/10.1515/crll.1882.92.156

[2] Hertz, H. (1896) Translated Work: On the Contact of Elastic Solids and on Hardness, \#6 in Miscellaneous Papers by H. Hertz, Ed. P. Lenard. Physics Publisher, London, New York Macmillan and Co., New York, 163-183.

https://archive.org/details/cu31924012500306

[3] Sneddon, I.N. (1965) The Relation between Load and Penetration in the Axisymmetric Boussinesq Problem for a Punch of Arbitrary Profile. International Journal of Engineering Science, 3, 47-57. https://doi.org/10.1016/0020-7225(65)90019-4

[4] Johnson, K.L. (1985) Contact Mechanics. Cambridge University Press, Cambridge.

[5] Kaupp, G. (2019) The Loading Curve of Spherical Indentations Is Not a Parabola and Flat Punch Is Linear. Advances in Materials Physics and Chemistry, 9, 141-157. https://doi.org/10.4236/ampc.2019.99012

[6] Ebenstein, D.M. and Wahl, K.J. (2006) A Comparison of JKR-Based Methods to Analyze Quasi-Static and Dynamic Indentation Force Curves. Journal of Colloid 
and Interface Science, 98, 652-662. https://doi.org/10.1016/j.jcis.2005.12.062

[7] Kaupp, G. (2020) Valid Geometric Solutions for Indentations with Algebraic Calculations. Advances in Pure Mathematics, 10, 322-336.

https://doi.org/10.4236/apm.2020.105019

Erratum in 10, 545-546. https://doi.org/10.4236/apm.2020.109034

[8] Bradby, J.E., Williams, J.S., Wong-Leung, J., Swain, M.V. and Munroe, P. (2002) Nanoindentation-Induced Deformation of Germanium. Applied Physics Letters, 80, 2651-2653. https://doi.org/10.1063/1.1469660

[9] Kaupp, G. (2017) Dilemma between Physics and ISO Elastic Indentation Modulus. Journal of Material Sciences and Engineering, 6, 402-405.

https://doi.org/10.4172/2169-0022.1000402

[10] Kaupp, G. (2020) Indentation onto Stishovite $\left(\mathrm{SiO}_{2}\right), \mathrm{MgO}$, and a Covered Superalloy: "Pop-In" Repair, Phase-Transition Onsets, Polymorph Energies, and Transition Energies. Advances in Materials Physics and Chemistry, 10, 77-95. https://doi.org/10.4236/ampc.2020.103007

[11] Kaupp, G. (2016) The Physical Foundation of $F_{\mathrm{N}}=k h^{3 / 2}$ for Conical/Pyramidal Indentation Loading Curves. Scanning, 38, 177-179. https://doi.org/10.1002/sca.21223

[12] Kucheyev, S.O., Bradby, J.E., Williams, J.S. Jagadish, C. and Swain, M.V. (2002). Mechanical Deformation of Single-Crystal ZnO. Applied Physics Letters, 80, 956-958. https://doi.org/10.1063/1.1448175

[13] Bradby, J.E., Kucheyev, S.O., Williams, J.S., Wong-Leung, J., Swain, M.V., Munroe, P., Li, G. and Phillips, M.R. (2002) Indentation-Induced Damage in GaN Epilayers. Applied Physics Letters, 80, 383-385. https://doi.org/10.1063/1.1436280

[14] Huang, J., Xu, K., Gong, X.J., Wang, J.F., Fan, Y.M., Liu, J.Q., Zeng, X.H., Ren, G.Q., Zhou, T.F. and Yang, H. (2011) Dislocation Cross-Slip in GaN Single Crystals Under Nanoindentation. Applied Physics Letters, 98, Article ID: 221906.

https://doi.org/10.1063/1.3593381

[15] Kaupp, G. (2013) Penetration Resistance: A New Approach to the Energetics of Indentations. Scanning, 35, 392-401. https://doi.org/10.1002/sca.21080

[16] Duzynska, A., Hrubiak, R., Drozd, V., Teisseyre, H., et al. (2012) The Structural and Optical Properties of ZnO Bulk and Nanocrystals Under High Pressure. High Pressure Research: An International Journal, 32, 354-363. https://doi.org/10.1080/08957959.2012.700308

[17] Decremps, F., Zhang, J. and Liebermann, R.C. (2000) New Phase Boundary and High-Pressure Thermoelasticity of ZnO. Europhysics Letters, 51 268-274.

https://doi.org/10.1209/epl/i2000-00347-0

[18] Vins, F., Lamiel-Garcia, O., Illas, F. and Bromley, S.T. (2017) Size Dependent Structural and Polymorphic Transitions in ZnO: From Nanoclusters to Bulk. Nanoscale, 9, 10067-10074. https://doi.org/10.1039/C7NR02818K

[19] Shabbir, S., Shaari, A., Bakhtiar, Haq, U., Ahmed, R. and Ahmed, M. (2020) Investigations of Novel Polymorphs of $\mathrm{ZnO}$ for Optoelectronic Applications. Optik, 206, Article ID: 164285. https://doi.org/10.1016/j.ijleo.2020.164285

[20] Ashrafi, A.B.M.A., Ueta, A., Avramescu, A., Kumano, H. and Suemune, I. (2000) Growth and Characterization of Hypothetical Zinc-Blende $\mathrm{ZnO}$ Films on GaAs (001) Substrates with ZnS Buffer Layers. Applied Physics Letters, 76, 550-552. https://doi.org/10.1063/1.125851

[21] Ashrafi, A. and Jagadish, C. (2007) Review of Zincblende ZnO: Stability of Metastable ZnO Phases. Journal of Applied Physics, 102, Article ID: 071101. 
https://doi.org/10.1063/1.2787957

[22] Ding, Y., Wang, Z.L., Sun, T. and Qui, J. (2007) Zinc Blende ZnO and Its Role in Nucleating Wurtzite Tetrapods and Twinned Nanowires. Applied Physics Letters, 90, Article ID: 153510. https://doi.org/10.1063/1.2722671

[23] Steplecaru, C.S., Martín-Gonzalez, M.S., Fernandez, J.F. and Costa-Krämer, J.L. (2010) How to Prevent Twin Formation in Epitaxial ZnO Thin Films Grown on c-Plane Sapphire. Thin Solid Films, 518, 4630-4633.

https://doi.org/10.1016/j.tsf.2009.12.047

[24] Bai, R., Pandaya, D.K., Chaudhary, S., Dhaka, V., Khayrudinov, V., Lemettinen, J., Kauppinen, C. and Lipsanen, H. (2019) Site-Specific Growth of Oriented ZnO Nanocrystal Arrays. Beilstein Journal of Nanotechnology, 10, 274-280.

https://doi.org/10.3762/bjnano.10.26

[25] Perlin, P., Jauberthie-Carillon, C., Itie, J.P., San Miguel, A., Grzegory, I. and Polian, A. (1992) Raman Scattering and X-Ray-Absorption Spectroscopy in Gallium Nitride under High Pressure. Physical Review B, 45, 3-89.

https://doi.org/10.1103/PhysRevB.45.83

[26] Xia, H., Xia, Q. and Ruoff, A.L. (1993) High-Pressure Structure of Gallium Nitride: Wurtzite-to-Rocksalt Phase Transition. Physical Review B: Condensed Matter and Materials Physics, 47, 12925-12928. https://doi.org/10.1103/PhysRevB.47.12925

[27] Saad Saoud, F., Plenet, J.C., Louail, L. and Maouch, D. (2011). Mechanism of the Phase Transition in GaN under Pressure Up to 100GPa. Computational and Theoretical Chemistry, 964, 65-71. https://doi.org/10.1016/j.comptc.2010.11.037

[28] Selke, H., Kirchner, V., Heinke, H., Einfeld, S., Ryder, P.L. and Hommel, D. (2000) Polytypism in Epitaxially Grown Gallium Nitride. Journal of Crystal Growth, 208, 57-64. https://doi.org/10.1016/S0022-0248(99)00462-5

[29] Al Balushi, Z.Y., Wang, K., Ghosh, R.K., Vila, R.A., Eichfeld, S.M., Caldwell, J.D. Qin, X., et al. (2016) Two-Dimensional Gallium Nitride Realized via Graphene Encapsulation. Nature Materials, 15, 1166-1171.

http://www.nature.com/naturematerials https://doi.org/10.1038/nmat4742

[30] Johnson, K.L., Kendall, K. and Roberts, A.D. (1971) Surface Energy and the Contact of Elastic Solids. Proceedings of the Royal Society A: Mathematical, Physical and Engineering Sciences, 324, 301-323. https://doi.org/10.1098/rspa.1971.0141

[31] Kaupp, G. (2013) Penetration Resistance and Penetrability in Pyramidal (Nano)Indentations. Scanning, 35, 88-111. https://doi.org/10.1002/sca.21038

[32] Meinhard, H. and Grau, P. (2004) Viscosity of Glass at High Contact Pressure during Indentation Experiments. International Journal of Materials Research, 95, 326-334. https://doi.org/10.3139/146.017957

[33] Le Bourhis, E. and Patriarche, G. (2005) Nanoindentation Investigation of Solid-Solution Strengthening in III-V Semiconductor Alloys. International Journal of Materials Research, 96, 1237-1241. https://doi.org/10.3139/146.101167

[34] Xu, L., Kong, L., Zhao, H., Wang, S., Lu, S. and Qian, L. (2019) Mechanical Behavior of Undoped $\mathrm{n}$-Type GaAs under the Indentation of Berkovich and Flat-Tip Indenters. Materials, 12, 1192-1201. https://doi.org/10.3390/ma12071192

[35] Field, J.S. and Swain, M.V. (1995) Determining the Mechanical Properties of Small Volumes of Material from Submicrometer Spherical Indentations. Journal of Materials Research, 10, 101-112. https://doi.org/10.1557/JMR.1995.0101

[36] Weppelmann, E.R., Field, J.S. and Swain, M.V. (1993) Observation Analysis and 
Simulation of the Hysteresis of Silicon Using Ultra-Micro-Indentation with Spherical Indenters. Journal of Materials Research, 8, 830-840.

https://doi.org/10.1557/JMR.1993.0830

[37] Page, T.F., Warren, C.O. and McHarger, J. (1992) The Deformation Behavior of Ceramic Crystals Subjected to Very Low Load (Nano)Indentation. Journal of Materials Research, 7, 450-473. https://doi.org/10.1557/JMR.1992.0450

[38] Hainsworth, S.V., Chandler, H.W. and Page, T.F. (1996) Analysis of Nanoindentation Load-Displacement Loading Curves. Journal of Materials Research, 11, 1987-1995. https://doi.org/10.1557/JMR.1996.0250

[39] Kaupp, G. (2019) Physical Nanoindentation: From Penetration Resistance to Phase-Transition Energies. Advances in Materials Physics and Chemistry, 9, 103-122. https://doi.org/10.4236/ampc.2019.96009

[40] Shiwa, M., Weppelmann, E., Munz, D., Swain, M.V. and Kishi, T. (1996) Acoustic Emission and Precision Force-Displacement Observation of Pointed and Spherical Indentation of Silicon and TiN Film on Silicon. Journal of Materials Science, 31, 5985-5991. https://doi.org/10.1007/BF01152149

[41] Datye, A. and Lin, H.T. (2017) Energy Analysis of Spherical and Berkovich Indentation Contact Damage in Commercial Polycrystalline Silicon Carbide. Ceramics International, 43A, 800-809.

https://doi.org/10.1016/j.ceramint.2016.10.011

[42] Gorai, S. and Bhattachara, C. (2019) Shock Induced Phase Transition in SiC Polytypes. Journal of Applied Physics, 125, Article ID: 185903.

https://doi.org/10.1063/1.5090808

[43] Montagne, A., Tromas, C., Audurier, V. and Woirgard, J. (2008) A New Insight on Reversible Deformation and Incipient Plasticity during Nanoindentation Test in MgO. Journal of Materials Research, 24, 883-889. https://doi.org/10.1557/jmr.2009.0127

[44] Field, J.S. and Swain, M.V. (1993) A Simple Predictive Model for Spherical Indentation. Journal of Materials Research, 8, 297-306. https://doi.org/10.1557/JMR.1993.0297

[45] Idriss, M., Bartier, O., Mauvoisin, G. and Hernot, X. (2019) Determining the Stress Level of Monotonic Plastically Pre-Hardened Metal Sheets Using the Spherical Instrumented Indentation Technique. Journal of Mechanical Science and Technology, 33, 183-195. https://doi.org/10.1007/s12206-018-1218-1 